\title{
Respiratory symptoms and lung function in alumina refinery employees
} A William Musk, Nicholas H de Klerk, Jeremy R Beach, Lin Fritschi, Malcolm R Sim,
Geza Benke, Michael Abramson, John J McNeil
Department of Public Health, University of Western Australia A W Musk

Department of

Medicine

A W Musk

N H de Klerk

Department of Epidemiology and

Preventive Medicine, Monash University,

Australia

J R Beach

L Fritschi

M R Sim

G Benke

M Abramson

J J McNeil

Correspondence to: Dr A W Musk, Department of Respiratory Medicine, Sir Charles Gairdner Hospital, Nedlands 6009, Western Australia

email

Bill.Musk@health.wa.gov.au

Accepted 29 November 1999
Abstract

Objectives-Employees in alumina refineries are known to be exposed to a number of potential respiratory irritants, particularly caustic mist and bauxite and alumina dusts. To examine the prevalence of work related respiratory symptoms and lung function in alumina refinery employees and relate these to their jobs.

Methods-2964 current employees of three alumina refineries in Western Australia were invited to participate in a cross sectional study, and $89 \%$ responded. Subjects were given a questionnaire on respiratory symptoms, smoking, and occupations with additional questions on temporal relations between respiratory symptoms and work. Forced expiratory volume in 1 second $\left(F E V_{1}\right)$ and forced vital capacity (FVC) were measured with a rolling seal spirometer. Atopy was assessed with prick skin tests for common allergens. Associations between work and symptoms were assessed with Cox's regression to estimate prevalence ratios, and between work and lung function with linear regression.

Results-Work related wheeze, chest tightness, shortness of breath, and rhinitis were reported by $5.0 \%, 3.5 \%, 2.5 \%$, and $9.5 \%$ of participants respectively. After adjustment for age, smoking, and atopy, most groups of production employees reported a greater prevalence of work related symptoms than did office employees. After adjustment for age, smoking, height, and atopy, subjects reporting work related wheeze, chest tightness, and shortness of breath had significantly lower mean levels of $\mathrm{FEV}_{1}(186,162$, and $272 \mathrm{ml}$ respectively) than subjects without these symptoms. Prevalence of most work related symptoms was higher at refinery 2 than at the other two refineries, but subjects at this refinery had an adjusted mean $\mathrm{FEV}_{1}>60 \mathrm{ml}$ higher than the others. Significant differences in FVC and FEV $I$ FVC ratio, but not $\mathrm{FEV}_{1}$, were found between different process groups.

Conclusions-There were significant differences in work related symptoms and lung function between process groups and refineries, but these were mostly not consistent. Undefined selection factors and underlying population differences may account for some of these findings but workplace exposures may also contribute. The differences identified between groups were unlikely to be clinically of note.
(Occup Environ Med 2000;57:279-283)

Keywords: aluminium; alumina; bauxite; caustic mist; occupational epidemiology

In alumina refineries, alumina (aluminium oxide) is refined from bauxite with the Bayer process. ${ }^{1}$ There are several stages in the refining process: firstly, the bauxite is crushed and digested in hot caustic soda (digestion); next the heavy unwanted organic and inorganic contaminants are removed (clarification), and the residue is removed to large tanks or lakes (residue); alumina hydrate is then precipitated from the slurry with seeding by alumina crystals (precipitation); and finally the alumina hydrate is heated to remove water which leaves alumina dust (calcination). Although the process is highly automated tanks, pipes, and some machinery often need to be cleaned by descaling.

Alumina refinery employees are known to be exposed to bauxite and alumina dusts (both often considered to be only nuisance dusts), and caustic soda mist. ${ }^{1}$ Caustic mist is considered to be an irritant to the eyes, mucous membranes, and skin although there have been no reports specifically of these effects among alumina refinery workers. Consequently, alumina refinery employees may be at risk of excess respiratory morbidity.

One previous cross sectional epidemiological study of respiratory morbidity in alumina refinery employees showed a pattern of decreasing lung function with increasing duration of exposure and increasing estimated cumulative exposure to refinery dust, particularly among employees with high exposure who had never smoked. ${ }^{2}$ In a later study at the same refinery, non-smoking employees with high dust exposure also showed increased prevalence of profusion of small opacities (ILO score $\geqslant 1 / 0$ ) on chest radiographs. ${ }^{3}$ No exploration of the possible effects of exposure to caustic mist was made in these studies.

As part of an industry wide series of studies of respiratory morbidity and mortality in the aluminium industry in Australia (Healthwise), ${ }^{4}$ we conducted a survey of workers at three alumina refineries in Western Australia to find if there was any evidence of work related respiratory disease in the workforce. The survey comprised measures of the prevalence of respiratory symptoms and smoking, occupational histories, as well as measures of pulmonary function, and prick skin tests to common allergens to identify atopic people. The aims of the study were: $(a)$ to examine the prevalence of respiratory symptoms; (b) to measure lung 


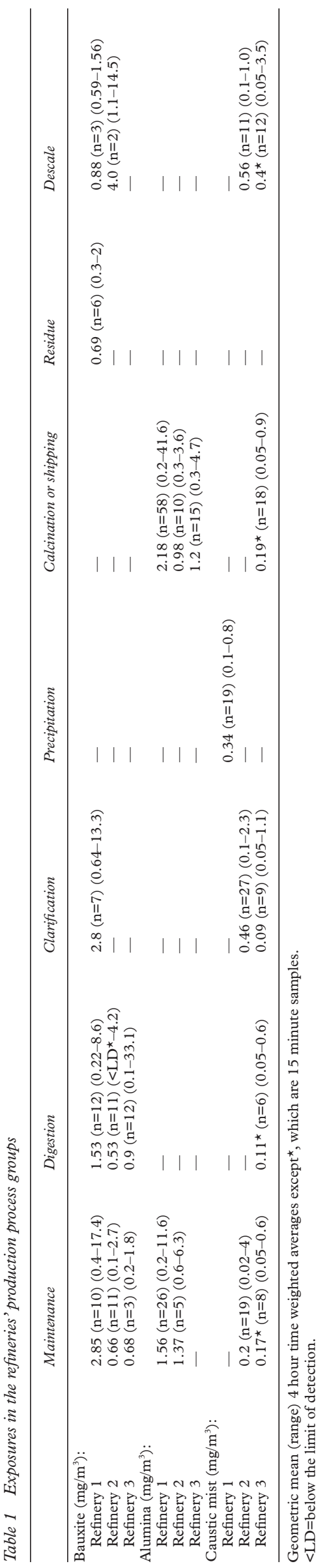

function; and (c) to compare these variables between particular process groups.

\section{Subjects and methods}

SUBJECTS

Subjects comprised all current employees of three alumina refineries in Western Australia. A total of 2964 employees were invited to take part in the study, of whom 2639 (89\%) participated. The study was approved by the ethics committees of the University of Western Australia and Monash University.

\section{DATA COLLECTION}

The study was cross sectional and was conducted between September 1995 and May 1996, avoiding the winter period. All subjects were given a modified British Medical Research Council questionnaire on respiratory symptoms and smoking by the same team of trained interviewers. ${ }^{5}$ Rhinitis was taken as frequent sneezing and an itchy running nose. Chronic bronchitis was defined as cough or sputum (or both) on most days for at least 3 months. Current smokers had smoked at least one cigarette daily for at least 1 year, and ex-smokers had stopped smoking for a period of at least 3 months.

Participants were asked additional questions about the temporal relation between any reported symptoms and their work. Subjects who answered that a symptom was better at the beginning of the working week, or on days when away from work, or when on holidays, were considered to have a work related symptom.

\section{EXPOSURE ASSESSMENT}

A detailed occupational history was taken from each employee to determine work site, operating centre, department, job title, and tasks performed. With pre-existing occupational hygiene data, jobs and job tasks were divided into process groups that defined broad groupings of similar exposures to the dusts and potential irritants of interest. These consisted principally of exposure to bauxite, alumina dusts and caustic mist (table 1). There were no measurements available for the administration and powerhouse process groups because the local occupational hygienists considered these jobs to be unexposed to the contaminants of interest to this study.

\section{MEASUREMENT OF LUNG FUNCTION}

Forced expiratory volume in 1 second $\left(\mathrm{FEV}_{1}\right)$ and forced vital capacity (FVC) were measured during work hours with a rolling seal spirometer (Graseby Anderson, USA) according to the recommendations of the American Thoracic Society. ${ }^{6}$ The calibration of the spirometers was checked at the beginning and end of each testing session with a 3 litre syringe to ensure that they remained within the limits of accuracy recommended in the ATS guidelines. The spirometers were also regularly tested for leaks (at least weekly and whenever the face plate was removed for cleaning).

\section{ASSESSMENT OF ATOPY}

Atopy was measured with prick skin tests for house dust mite, mixed grasses, mould mix, 
and cat dander allergens (Bayer, Sydney, Australia). Subjects with one or more wheals with a mean diameter $\geqslant 3 \mathrm{~mm}$ greater than the negative control were considered to be atopic. ${ }^{7}$

\section{STATISTICAL METHODS}

Prevalence ratios were used to examine the associations between each of the four work related symptoms and explanatory covariates and were estimated with Cox's regression as suggested by Thompson et al. ${ }^{8}$ The models included terms for process group, refinery site, age, smoking, and atopy. Overall differences between refineries and process groups were tested with these model terms. The interaction of refinery or process group with other variables was used to test if associations were consistent in the different locations, and the interaction of refinery and process group was used to examine whether the associations of process group with the various response variables were consistent in the different refineries. Smoking was included as one categorical variable for current smokers, exsmokers, and never smokers. Two work exposure variables were examined: total years employment with the company and current process group. All analyses were repeated for non-work related respiratory symptoms-namely, chronic bronchitis, wheeze in the past 12 months, wheeze with shortness of breath, seasonal rhinitis, perennial rhinitis, chest tightness in the past 12

Table 2 Distribution of potential confounding factors

\begin{tabular}{|c|c|c|c|c|c|c|}
\hline & Subjects & $\begin{array}{l}\text { Current } \\
\text { smokers (\%) }\end{array}$ & $\begin{array}{l}\text { Schooling } \\
>10 y(\%)\end{array}$ & $\begin{array}{l}\text { Atopy } \\
(\%)\end{array}$ & $\begin{array}{l}\text { Mean height } \\
(\mathrm{cm})\end{array}$ & $\begin{array}{l}\text { Mean age } \\
(y)\end{array}$ \\
\hline \multicolumn{7}{|l|}{ Refineries: } \\
\hline Refinery 1 & 927 & 22 & 47 & 42 & 176.6 & 41.3 \\
\hline Refinery 2 & 1005 & 23 & 48 & 50 & 176.9 & 39.6 \\
\hline Refinery 3 & 456 & 27 & 51 & 37 & 177.1 & 37.3 \\
\hline $\mathrm{p}$ Value ${ }^{\star}$ & & 0.07 & 0.41 & $<0.001$ & 0.31 & $<0.001$ \\
\hline \multicolumn{7}{|l|}{ Process groups: } \\
\hline $\begin{array}{l}\text { Office or } \\
\text { administration }\end{array}$ & 519 & 15 & 72 & 48 & 177.5 & 41.5 \\
\hline Powerhouse & 106 & 19 & 39 & 34 & 175.3 & 45.9 \\
\hline Maintenance & 897 & 25 & 42 & 47 & 176.6 & 38.2 \\
\hline Digestion & 205 & 30 & 39 & 40 & 176.8 & 39.3 \\
\hline Clarification & 202 & 33 & 45 & 37 & 177.0 & 39.8 \\
\hline Precipitation & 152 & 24 & 41 & 43 & 177.4 & 39.6 \\
\hline $\begin{array}{l}\text { Calcination or } \\
\text { shipping }\end{array}$ & 186 & 23 & 41 & 43 & 176.9 & 40.8 \\
\hline Residue & 39 & 21 & 36 & 49 & 176.7 & 43.7 \\
\hline Descale & 82 & 32 & 39 & 40 & 176.4 & 36.6 \\
\hline $\mathrm{p}$ Value ${ }^{\star}$ & & $<0.001$ & $<0.001$ & 0.02 & 0.11 & $<0.001$ \\
\hline
\end{tabular}

${ }^{\star} \chi^{2}$ Test for difference in proportions or $F$ test for difference in means between groups.

Table 3 Lung function groupst in refineries and process

\begin{tabular}{|c|c|c|c|}
\hline & $\begin{array}{l}F E V_{1}(\mathrm{ml}) \\
(\% \text { predicted })\end{array}$ & $\begin{array}{l}F V C(m l) \\
(\% \text { predicted })\end{array}$ & $\begin{array}{l}F E V_{l} / F V C \\
(\%)\end{array}$ \\
\hline \multicolumn{4}{|l|}{ Refineries: } \\
\hline Refinery 1 & $-47.9 \quad(104.7)$ & $-151.5 \quad(104.8)$ & 1.45 \\
\hline Refinery 2 & $60.6 \quad(107.7)$ & $118.3 \quad(110.8)$ & -0.67 \\
\hline Refinery 3 & $-37.1 \quad(105.5)$ & $43.8 \quad(109.5)$ & -1.44 \\
\hline p Value ${ }^{\star}$ & $<0.001$ & $<0.001$ & $<0.001$ \\
\hline \multicolumn{4}{|l|}{ Process groups: } \\
\hline Office or administration & 8.0 & -36.6 & 0.81 \\
\hline Powerhouse & -30.7 & -83.4 & 0.77 \\
\hline Maintenance & -20.5 & -10.0 & -0.30 \\
\hline Digestion & -26.6 & 26.7 & -0.89 \\
\hline Clarification & 21.0 & 100.0 & -1.20 \\
\hline Precipitation & 20.5 & -42.0 & 1.12 \\
\hline Calcification or shipping & 62.5 & 84.6 & -0.09 \\
\hline Residue & -11.5 & -116.3 & 1.41 \\
\hline Descale & 55.1 & 76.0 & -0.14 \\
\hline $\mathrm{p}$ Value ${ }^{\star}$ & 0.55 & 0.03 & $<0.001$ \\
\hline
\end{tabular}

${ }^{\star} F$ test for difference in means.

$\dagger$ Difference from overall mean, adjusted for age, height, smoking, and atopy. months, and dyspnoea grade 2 or worse. This was done to investigate consistency of findings for both work related and non-work related symptoms, especially for those where a temporal relation to work (such as symptoms of chronic bronchitis) would not be expected.

Predicted values for lung function were obtained from published regression equations, which include terms for the decline in lung function with age and its increase with height. ${ }^{9}$ The associations of the same explanatory covariates with $\mathrm{FEV}_{1}, \mathrm{FVC}$, and the $\mathrm{FEV}_{1} / \mathrm{FVC}$ ratio were examined with multiple linear regression after a similar analysis strategy to that used for symptoms, but with additional adjustment for height, a major determinant of lung function. Differences in lung function associated with work related symptoms were similarly estimated.

All statistical analysis was performed with SPSS for Windows. ${ }^{10}$

\section{Results}

Of 2964 employees at the refineries, 2388 male and 192 female subjects provided complete data sets representing an $87 \%$ participation rate. One hundred and thirty eight $(72 \%)$ of the women worked in the administration process group. It was therefore decided to confine further analysis to men only. The median duration of employment was 10 years (range $0-33$ years).

There were significant differences between refineries in mean age and the prevalence of atopy, and between process groups in the prevalence of current smoking, mean age, and years of schooling (table 2).

Overall levels of $\mathrm{FEV}_{1}$ and FVC were $>100 \%$ predicted in all refineries (table 3). After internal adjustment for age, height, smoking, and atopy, refinery 1 had the lowest $\mathrm{FEV}_{1}$ and FVC, and refinery 2 the highest. Mean FVC was $270 \mathrm{ml}$ higher and mean $\mathrm{FEV}_{1} 109 \mathrm{ml}$ higher in refinery 2 than refinery 1 (table 3 ). The $\mathrm{FEV}_{1} / \mathrm{FVC}$ ratio order was reversed. There were no significant differences between process groups for adjusted $\mathrm{FEV}_{1}$, but there were for $\mathrm{FVC}$ and $\mathrm{FEV}_{1} / \mathrm{FVC}$ ratio: employees in the clarification process had the highest adjusted $\mathrm{FVC}$ and the lowest $\mathrm{FEV}_{1} / \mathrm{FVC}$ ratio (table 3 ). There was no significant effect of duration of employment on any measure of lung function.

Examination of interaction effects of process group and refinery indicated that there were no significant differences between refineries in the associations between process groups and lung function ( $p>0.2$ for all analyses).

Work related wheeze and work related rhinitis were significantly more prevalent in refinery 2 than in the other two refineries, and work related chest tightness was also more commonly reported there, although this was not significant (table 4). Rhinitis was the most commonly reported work related symptom and was more prevalent in all production employees apart from the residue group.

The presence of atopy on prick skin tests was significantly associated with reported work related wheeze, with a prevalence ratio (PR) of 1.8 (95\% confidence interval $(95 \% \mathrm{CI}) 1.2$ to 2.6), and atopy was also more common in 
Table 4 Prevalence of work related symptoms by refinery and process group

\begin{tabular}{|c|c|c|c|c|}
\hline & \multicolumn{4}{|c|}{ Work related symptoms (\% of subjects) } \\
\hline & Wheeze & $\begin{array}{l}\text { Chest } \\
\text { tightness }\end{array}$ & $\begin{array}{l}\text { Shortness } \\
\text { of breath }\end{array}$ & Rhinitis \\
\hline \multicolumn{5}{|l|}{ Refineries: } \\
\hline Refinery 1 & 3.2 & 2.5 & 2.8 & 8.0 \\
\hline Refinery 2 & 7.2 & 4.3 & 2.4 & 11.6 \\
\hline Refinery 3 & 3.5 & 2.6 & 2.0 & 7.7 \\
\hline p Value ${ }^{\star}$ & $<0.001$ & 0.06 & 0.63 & 0.008 \\
\hline \multicolumn{5}{|l|}{ Process groups: } \\
\hline Office or administration & 2.5 & 2.3 & 1.9 & 5.6 \\
\hline Powerhouse & 1.9 & 1.9 & 0.9 & 4.7 \\
\hline Maintenance & 5.4 & 2.8 & 2.1 & 11.7 \\
\hline Digestion & 6.3 & 4.9 & 2.4 & 7.3 \\
\hline Clarification & 5.0 & 4.5 & 3.0 & 10.4 \\
\hline Precipitation & 7.9 & 4.6 & 5.9 & 13.2 \\
\hline Calcification or shipping & 7.5 & 4.3 & 2.2 & 10.2 \\
\hline Residue & 2.6 & 5.1 & 7.7 & 5.1 \\
\hline Descale & 6.1 & 3.7 & 2.4 & 12.2 \\
\hline $\mathrm{p}$ Value ${ }^{\star}$ & 0.04 & 0.50 & 0.07 & 0.004 \\
\hline All employees & 4.9 & 3.3 & 2.5 & 9.5 \\
\hline
\end{tabular}

${ }^{\star} \chi^{2}$ Test for difference in proportions.

subjects reporting other work related symptoms (table 5). Current smoking was associated with a large increase in the prevalence of reported work related wheeze (PR 3.1, 95\% CI 1.9 to 5.0) and with lesser increases in the other symptoms.

After adjustment for age, smoking, atopy, and process group, work related symptoms were reported significantly more commonly in refinery 2 , particularly wheeze, but also chest tightness and rhinitis (table 5). Precipitation employees had significantly increased reports of work related shortness of breath, wheeze, and rhinitis compared with administration employees. Work related wheeze was also more commonly reported by digestion and calcination or shipping employees. Work related rhinitis was widely reported by production employees. There was no significant or appreciable effect of duration of employment on the reporting of any work related symptoms.
The presence of these work related symptoms was significantly associated with levels of lung function: work related shortness of breath was associated with lower levels of $\mathrm{FEV}_{1}$ by 272 $\mathrm{ml}$, of $\mathrm{FVC}$ by $207 \mathrm{ml}$, and of $\mathrm{FEV}_{1} / \mathrm{FVC}$ ratio by $2.6 \%$ (table 6 ). Similarly, work related wheeze was associated with an $\mathrm{FEV}_{1}$ which was $186 \mathrm{ml}$ lower and an $\mathrm{FEV}_{1} / \mathrm{FVC}$ ratio which was 3\% lower. There were similar changes associated with chest tightness (table 6). Work related rhinitis was associated with only relatively small changes in mean lung function.

Results from analyses of all reported symptoms were broadly similar to those obtained when looking at work related symptoms for wheeze, chest tightness, and dyspnoea. Chronic bronchitis was reported more commonly at refinery 2 (PR 1.4, 95\% CI 1.04 to 1.80) and was associated with decreased lung function although this association was not significant $\left(\mathrm{FEV}_{1}\right.$ lower by $32 \mathrm{ml}, 95 \% \mathrm{CI}-97$ to 34). Seasonal and perennial rhinitis indicated different associations. For perennial rhinitis there were no significant differences between refineries but large differences between process groups, whereas for seasonal rhinitis there were significant differences between refineries (with the prevalence of refinery 2 significantly increased (PR 1.3, 95\% CI 1.07 to 1.59)) but no differences between process groups.

As well as effects on work related symptoms, atopy and smoking also were significantly associated with lung function. Atopic subjects had a lower mean $\mathrm{FEV}_{1} / \mathrm{FVC}$ ratio, $(0.8,95 \%$ CI 0.2 to 1.3 ) but were not significantly different in either mean $\mathrm{FEV}_{1}$ or FVC. Current smoking was associated with a significantly lower mean $\mathrm{FEV}_{1}(194 \mathrm{ml})$, mean FVC (42 ml), and mean $\mathrm{FEV}_{1} / \mathrm{FVC}(2.3 \%)$. There were lesser deficits

Table 5 Associations of refineries, process groups, and work related respiratory symptoms

\begin{tabular}{|c|c|c|c|c|}
\hline & \multicolumn{4}{|c|}{ Work related symptoms $P R(95 \%$ CI $) \dagger$} \\
\hline & Wheeze & Chest tightness & Shortness of breath & Rhinitis \\
\hline \multicolumn{5}{|l|}{ Refineries: } \\
\hline Refinery 1 & 1.0 & 1.0 & 1.0 & 1.0 \\
\hline Refinery 2 & $2.1(1.3$ to 3.2$)$ & $1.6(1.0$ to 2.7$)$ & $1.0(0.5$ to 1.7$)$ & $1.4(1.0$ to 1.8$)$ \\
\hline Refinery 3 & $1.0(0.6$ to 2.0$)$ & $1.0(0.5$ to 2.0$)$ & $1.0(0.4$ to 2.2$)$ & $1.0(0.6$ to 1.5$)$ \\
\hline $\mathrm{p}$ Value ${ }^{\star}$ & 0.001 & 0.10 & 0.99 & 0.06 \\
\hline \multicolumn{5}{|l|}{ Process groups: } \\
\hline Office or administration & 1.0 & 1.0 & 1.0 & 1.0 \\
\hline Powerhouse & $0.8(0.2$ to 3.5$)$ & $0.8(0.2$ to 3.7$)$ & $0.4(0.1$ to 3.1$)$ & $0.9(0.3$ to 2.4$)$ \\
\hline Maintenance & $1.7(0.9$ to 3.2$)$ & $1.0(0.5$ to 2.1$)$ & $1.1(0.5$ to 2.5$)$ & $2.0(1.3$ to 3.0$)$ \\
\hline Digestion & $2.2(1.0$ to 4.7$)$ & $1.9(0.8$ to 4.4$)$ & $1.2(0.4$ to 3.7$)$ & $1.3(0.7$ to 2.5$)$ \\
\hline Clarification & $1.6(0.7$ to 3.6$)$ & $1.7(0.7$ to 4.0$)$ & $1.5(0.5$ to 4.2$)$ & $1.8(1.0$ to 3.2$)$ \\
\hline Precipitation & $2.8(1.3$ to 6.2$)$ & $1.7(0.7$ to 4.4$)$ & $2.9(1.2$ to 7.4$)$ & 2.3 (1.3 to 4.2$)$ \\
\hline Calcification or shipping & $2.9(1.4$ to 6.3$)$ & $1.8(0.7$ to 4.4$)$ & $1.0(0.3$ to 3.4$)$ & $1.9(1.1$ to 3.5$)$ \\
\hline Residue & $0.9(0.1$ to 6.7$)$ & $1.9(0.4$ to 8.7$)$ & $3.4(0.9$ to 12.7$)$ & $0.9(0.2$ to 3.9$)$ \\
\hline Descale & $1.9(0.7$ to 5.3$)$ & $1.3(0.4$ to 4.8$)$ & $1.4(0.3$ to 6.6$)$ & $2.0(1.0$ to 4.2$)$ \\
\hline p Value* & 0.11 & 0.65 & 0.24 & 0.02 \\
\hline Atopy (skin prick test) & $1.8(1.2$ to 2.6$)$ & $1.3(0.8$ to 2.1$)$ & $1.0(0.6$ to 1.7$)$ & $1.3(1.0$ to 1.6$)$ \\
\hline
\end{tabular}

${ }^{\star} \mathrm{p}$ Value for heterogeneity of PRs.

†PR $(95 \% \mathrm{CI})$ adjusted for age, smoking, atopy, and each other.

Table 6 Estimated differences in mean lung function for subjects with work related symptoms

\begin{tabular}{|c|c|c|c|c|}
\hline \multirow[b]{2}{*}{ Lung function } & \multicolumn{4}{|l|}{ Difference ${ }^{\star}(95 \%$ CI $)$} \\
\hline & Wheeze & Chest tightness & Shortness of breath & Rhinitis \\
\hline $\mathrm{FEV}_{1}(\mathrm{ml})$ & $-186(-92$ to -281$)$ & $-162(-47$ to -277$)$ & $-272(-142$ to -403$)$ & $-32(-101$ to 37$)$ \\
\hline $\mathrm{FVC}(\mathrm{ml})$ & $-56(-166$ to 53$)$ & $-50(-183$ to 84$)$ & $-207(-55$ to -359$)$ & $-42(-122$ to 39$)$ \\
\hline $\mathrm{FEV}_{1} / \mathrm{FVC}$ ratio $(\%)$ & $-3.02(-1.83$ to -4.21$)$ & $-2.67(-1.22$ to -4.13$)$ & $-2.58(-1.00$ to -4.30$)$ & $-0.06(-0.94$ to 0.82$)$ \\
\hline
\end{tabular}

*Adjusted for age, height, smoking, atopy, and refinery. 
for ex-smokers, which were only significant for a $1 \%$ reduction in $\mathrm{FEV}_{1} / \mathrm{FVC}$.

\section{Discussion}

Subjects from the three alumina refineries had good lung function compared with published predicted normal values. ${ }^{9}$

There was a significant increase in rhinitis among most groups of production employees compared with administration workers which is consistent with upper airway irritation caused by either dust or caustic mist. There were no significant deficits in lung function associated with this symptom.

There were also significantly higher frequencies of work related symptoms among precipitation employees. These symptoms were not associated with any significant deficits in lung function. Also, precipitation employees did not have the highest exposures to caustic mist (table 1), and available exposure data do not provide an explanation for why they would be more likely to report symptoms as being work related than other process groups.

Employees at refinery 2 reported a higher prevalence of work related symptoms than those at the other refineries, but employees at that refinery also had the highest levels of $\mathrm{FEV}_{1}$ and FVC. Average exposures at this refinery were relatively low compared with the other two refineries (table 1). Employees at refinery 2 were more likely to be atopic than employees at the other refineries, but this could not explain the differences in prevalence of symptoms as the increases in reported symptoms were not restricted to atopic subjects (the interaction term of refinery site and atopy was far from significant, $\mathrm{p}=0.75$ ), and remained similar after adjustment for atopy (table 5). It may be that these reflect differences in source populations, in selection procedures, or in unmeasured exposures at the different refineries. Seasonal factors were unlikely to account for these differences, as our data relate to work related symptoms.

Workplace exposures within some of the process groups in these three refineries were associated with work related upper and lower respiratory symptoms, consistent with known exposure to irritants such as caustic mist and particulates. These symptoms were associated with deficits in lung function with an obstructive pattern in those subjects with work related shortness of breath, wheeze, and chest tightness. These findings suggest that exposures at work are responsible for both the symptoms and impaired lung function, or alternatively, that subjects with lower levels of lung function are more likely to experience symptoms.

Smoking was associated with an increased prevalence of work related symptoms, and a deficit in the level of lung function among all employees. This is consistent with the known effects of smoking, and suggests that the other findings were real effects. Atopic subjects were also more likely to experience work related symptoms than non-atopic subjects and had a lower $\mathrm{FEV}_{1} / \mathrm{FVC}$ ratio, consistent with previous studies. ${ }^{11}$ The distribution of atopy between the various process groups and between refineries was uneven, raising the issue that selection factors before employment may account for some of the differences in symptom prevalence between groups. From these cross sectional data this possible selection bias could not be disentangled. Should there have been such a selection bias, however, it is likely to have operated in such a way as to increase the prevalence of symptoms among the office or administration process group rather than among the production workers as we found.

Although there was some evidence of airflow obstruction with reduced $\mathrm{FEV}_{1} / \mathrm{FVC}$ in some process groups, this reduction was not related to any one of the particular exposures that had been estimated for the process groups. The estimated differences in lung function between process groups were also small and unlikely to be of clinical significance.

This study is one of the only two studies of the respiratory health of alumina refinery employees. A previous study in an American refinery found a pattern of decreasing lung function with increasing total dust exposure. ${ }^{2}$ In our study, quantitative exposure indices could not be estimated at this stage, but there were no important decreases in lung function associated with work in any particular process groups, albeit these process groups represent a relatively crude estimate of exposure. Precise exposure estimates, based on specific exposures in each job and task in the refineries, are to be developed in the next phase of this study to further investigate the findings of these analyses based on process group only. However, the analyses in this paper do not suggest that work in an alumina refinery, in conditions similar to those pertaining at the time of this study, has any major adverse effects on respiratory health.

This study was funded by Alcoa of Australia, Portland Aluminium and KAAL Pt Henry. JRB was partly supported by the Society of Occupational Medicine Golden Jubilee Travelling Fellowship. We wish to thank Jill Dunstan, Shelley Fair, Kimberley Gibson, Anna Laffy, Sally Lindros, Kim Sutherland, Kimberley Gibson, Anna Laffy, Sally Lindros, Kim Sutherland,
and the liaison staff at the refineries for their contributions to and the liaison staff at the refineries for their contributions to
data collection. We also wish to acknowledge the invaluable data collection. We also wish to acknowledge the invaluable
contributions of Carol Barrie (administration), Geoff Aldred contributions of Carol Barrie (administration), Geoff Aldred
(data management), and the medical and hygiene staff at the three refineries. We are grateful to all the employees who took part in the study and their Trade Unions for their willing participation and support.

1 Burkin AR. Production of aluminium and alumina. Critical Reports on Applied Chemistry. Vol 20. New York: John Wiley, 1987

2 Townsend MC, Enterline PE, Sussman NB, et al. Pulmonary function in relation to total dust exposure at a bauxite refinery and alumina-based chemical products plant. $A m$ Rev Respir Dis 1985;132:1174-80.

3 Townsend MC, Sussman NB, Enterline PE, et al. Radiographic abnormalities in relation to total dust exposure at a bauxite refinery and alumina-based chemical products plant. Am Rev Respir Dis 1988;138:90-5.

4 Fritschi L, Beach J, Sim M, et al. Respiratory symptoms and lung function in two prebake aluminium smelters. Am F Ind Med (in press).

5 Medical Research Council. Questionnaire on respiratory symptoms. London: MRC, 1986.

6 American Thoracic Society. Standardisation of spirometry 1994 update. Am 7 Respir Crit Care Med 1995;152:1107-36. Dreborg S. Bronchial hyper-reactivity and skin sensitivity. Dreborg S. Bronchial hyper-reac
Clin Exp Allergy 1991;21:529.

8 Thompson ML, Myers JE, Kriebel D. Prevalence odds ratio or prevalence ratio in the analysis of cross-sectional data: what is to be done? Occup Environ Med 1998;55:272-7.

9 Cotes JE. Lung function [table 15.18]. Oxford: Blackwell, 1993. 10 Norusis MJ. SPSS for Windows. Chicago: SPSS, 1993.

11 Musk AW, Venables KM, Crook B, et al. Respiratory symptoms, lung function, and sensitisation to flour in a British bakery. Br f Ind Med 1989;46:636-42. 